\section{Botulinum toxin for muscle spasm after tetanus}

\author{
Tarek A-Z K Gaber MSc MRCP \\ Sailaja Mannemela MD
}

J R Soc Med 2005;98:63

Despite routine immunization, tetanus is still occasionally seen in the UK. After the acute episode, long-term neurological and musculoskeletal sequelae are common. ${ }^{1}$

\section{CASE HISTORY}

An intravenous drug user aged 28 sought advice because of trismus and then quickly deteriorated, developing generalized muscle spasms. Respiratory failure required artificial ventilation. Tetanus was diagnosed and he was treated with antibiotics and tetanus human immunoglobulins, together with diazepam and dantrolene to reduce muscle tone. After three weeks he was weaned off the artificial ventilation and transferred to a general medical ward where he improved slowly. However, he continued to have severe muscular rigidity with restriction of movements in the left elbow and both ankles, especially in dorsiflexion. For this we treated him with botulinum toxin (Dysport), a total of 1000 units injected into the left biceps brachii and brachioradialis and both gastrocnemius muscles. By the next day he had regained a full range of movement in both ankles, and elbow movements improved over the next few days. No side-effects were noted. Dantrolene was slowly withdrawn and within two weeks the patient was independently mobile with full movement in both elbows.

\section{COMMENT}

Like the tetanic neurotoxin tetanospasmin, botulinum toxin is the product of a clostridial species (Clostridium botulinum). The toxins are similar in structure and in mechanisms of action; the difference in clinical effects is attributable to their neurospecificities. Tetanus neurotoxin binds to the presynaptic membrane of the neuromuscular junction. It is internalized and transported retro-axonally to the spinal cord. The spastic paralysis induced by tetanus toxin is due to blockade of neurotransmitter release from spinal inhibitory interneurons. In contrast, the seven serotypes of botulinum neurotoxin act at the periphery, inhibiting acetylcholine release at the neuromuscular junction and inducing a flaccid paralysis. ${ }^{2}$

Leigh Infirmary, Greater Manchester WN7 1HS, UK

Correspondence to: $\mathrm{Dr} \mathrm{T}$ Gaber

E-mail: tarek.gaber@wwl.nhs.uk
Benzodiazepines and dantrolene are the drugs customarily used for muscle rigidity in tetanus ${ }^{3}$ but they act generally and are less useful for localized muscle rigidity of the sort experienced by our patient. The successful use of botulinum toxin to manage trismus in cephalic tetanus has been reported by Andrade et al. ${ }^{4}$ In our patient, use of this agent in peripheral muscle groups appeared to speed return to mobility and may well have helped prevent long-term joint deformities. More than half the survivors of tetanus have evidence of joint damage, which is thought to be due to repeated traction on the periosteum and violent stress on the joint. ${ }^{5}$

\section{REFERENCES}

1 Illis LS, Taylor FM. Neurological and electroencephalographic sequelae of tetanus. Lancet 1971;i:826-30

2 Pellizzari R, Rossetto O, Schiavo G, Montecucco C. Tetanus and botulinum neurotoxins; mechanism of action and therapeutic uses. Phil Trans R Soc B 1999;354:259-68

3 Tidyman M, Prichard JG, Deamer RL, Mac N. Adjunctive use of dantrolene in severe tetanus. Anesth Analg 1985;64:538-40

4 Andrade LA, Brucki SM. Botulinum toxin A for trismus in cephalic tetanus. Arq Neuropsiquiatr 1994;52:410-13

5 Luisto M, Zitting A, Tallroth K. Hyperostosis and osteoarthritis in patients surviving after tetanus. Skeletal Radiol 1994;23:31-5

\section{Ganglioneuromas in the adult scrotum}

\author{
S J Hanna MRCS ${ }^{1}$ A Muneer FRCS ${ }^{1}$ \\ S B Coghill FRCPath ${ }^{2}$ M A W Miller MD FRCS ${ }^{1}$
}

J R Soc Med 2005;98:63-64

Ganglioneuromas are benign tumours of the sympathetic nervous system. The occasional report of a paratesticular ganglioneuroma reflects embryological development.

\section{CASE HISTORY}

A man of 22 with insulin-dependent diabetes was referred for treatment of a phimosis secondary to balanitis xerotica obliterans. On routine examination he was found to have a smooth mobile mass in the right hemiscrotum. Scrotal ultrasound revealed several solid paratesticular lesions and a

Departments of ${ }^{1}$ Urology and ${ }^{2}$ Histopathology, Northampton General Hospital, Northampton NN1 5BD, UK

Correspondence to: Stephen Hanna, c/o Mr Miller's secretary, Integrated Surgery, Northampton General Hospital

E-mail: sjhanna@doctors.org.uk 


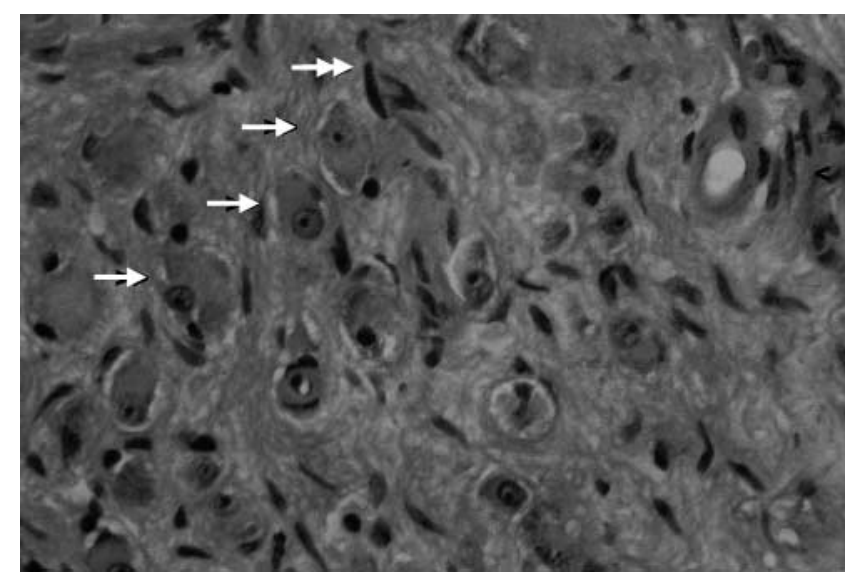

Figure 1 Photomicrograph of ganglion cell-rich area. Arrows point to ganglion cells $(\longrightarrow)$ and spindle cells $(\longrightarrow)$

scrotal exploration was undertaken. Five small masses were identified and removed. All were paratesticular; the testicle, epididymis and vas deferens were entirely normal.

On histological examination the lesions proved to be composed of spindle cells resembling those of a nerve sheath tumour, as well as large round cells with abundant amphophilic cytoplasm and a large slightly eccentrically placed nucleus with a prominent nucleolus (Figure 1). There were no immature elements. They were judged to represent benign ganglioneuromata. MRI scanning excluded the presence of any synchronous retroperitoneal tumour.

\section{COMMENT}

Ganglioneuromas are the most benign of the neuroblastic group of tumours, which include neuroblastoma and ganglioneuroblastoma. ${ }^{1}$ They consist of ganglion cells, Schwann cells and connective tissue. ${ }^{1,2}$ The most common locations are the posterior mediastinum, retroperitoneum, adrenal gland and neck. ${ }^{1}$ To our knowledge there have only been three previously reported cases of paratesticular ganglioneuromas, ${ }^{3-5}$ of which one was actually a composite tumour consisting of a ganglioneuroma and a malignant peripheral nerve sheath tumour. ${ }^{3}$ Two of these cases were in children, one ${ }^{5}$ in an adult.

The paratesticular region consists of many cell types and neoplasms arising therefrom are histologically heterogeneous. ${ }^{6}$ Tumours in this region present as discrete scrotal masses and may cause diagnostic confusion with testicular tumours. The commonest benign tumours are lipomata, adenomatoid tumours and leiomyomata; the more common malignant neoplasms are sarcomas, mesotheliomas, lymphomas and epididymal adenocarcinomas. ${ }^{6}$ This region may on rare occasions be the site of metastatic spread of other primary tumours, including lung, pleura, stomach, colon, prostate and kidney. ${ }^{6}$ Scrotal involvement by a tumour that commonly affects the retroperitoneum is not surprising in view of their common embryological origin. For this reason a patient with paratesticular ganglioneuromas should undergo imaging of the retroperitoneum and posterior mediastinum.

\section{REFERENCES}

1 Lonergan GJ, Schwab CM, Suarez ES, Carlson CL. Neuroblastoma, ganglioneuroblastoma, and ganglioneuroma: radiologic-pathologic correlation. Radiographics 2002;22:911-34

2 Jain M, Subha BS, Sethi S, Banga V, Bagga D. Retroperitoneal ganglioneuroma: report of a case diagnosed by fine-needle aspiration cytology, with review of the literature. Diagnostic Cytopathol 1999;21:194-6

3 Banks E, Moonahm Y, Brodhecker C, Goheen M. A malignant peripheral nerve sheath tumor in association with a paratesticular ganglioneuroma. Cancer 1989;64:1738-42

4 Ceroni V, Di Lüttichau F. Su una rar osservazione di ganglioneuroma paratesticolare nell'infanzia. Pathologica 1975;67:245-9

5 Pardalidis NP, Grigoriadis K, Papatsoris A, Kosmaoglou EV, Horti M. Primary paratesticular adult ganglioneuroma. Urology 2004;63:584

6 Khoubehi B, Mishra V, Ali M, Motiwala H, Karim O. Adult paratesticular tumours. BJU Int 2002;90:707-15

\section{A bloody mess: scalp lump misidentified}

\author{
Chern Beverly Brenda Lim MRCS MRCSEd ${ }^{1}$ \\ Vikas Khanduja MRCS(Glasg) ${ }^{2}$ \\ Jo-Anne Chin Aleong MRCPath ${ }^{3}$ \\ Michael Douek MD FRCS ${ }^{4}$
}

J R Soc Med 2005;98:64-65

Angiolymphoid hyperplasia with eosinophilia is seldom diagnosed preoperatively. When excising what seems to be a sebaceous cyst, the surgeon can be caught out by unexpected haemorrhage.

\section{CASE HISTORY}

An Asian man of 29 sought advice about an occipital lump that had been present for 5 years. It was occasionally itchy but painless. There were no other lumps and he gave no history of trauma to the site. On examination the lump was

\footnotetext{
${ }^{1}$ Departments of Surgical Oncology \& Technology, Imperial College, London; Departments of ${ }^{2}$ Orthopaedics and ${ }^{3}$ Pathology, The Royal London Hospital, London; ${ }^{4}$ Department of Surgery, Royal Free and University College Medical School, London, UK

Correspondence to: Mr Michael Douek, Department of Surgery, Charles Bell House, 67-73 Riding House Street, London W1W 7EJ, UK E-mail: m.douek@ucl.ac.uk
} 